\title{
On the identity dynamics of police legitimacy and public cooperation among a general population and a London street population
}

\author{
Arabella Kyprianides, UCL \\ Ben Bradford, UCL \\ Jonathan Jackson, LSE \& Sydney Law School \\ Julia Yesberg, UCL \\ Clifford Stott, Keele University \\ Matthew Radburn, Keele University
}

\begin{abstract}
Social identity is a core aspect of procedural justice theory, which predicts that fair treatment at the hands of power holders such as police expresses, communicates and generates feelings of inclusion, status and belonging within salient social categories. In turn, a sense of shared group membership with power-holders, with police officers as powerful symbolic representatives of "law-abiding society", engenders trust, legitimacy and cooperation. Yet, this aspect of the theory is rarely explicitly considered in empirical research. Moreover, the theory rests on the under-examined assumption that the police represent one fixed and stable superordinate group, including the often marginalised people with whom they interact, and that it is only superordinate identification that is important to legitimacy and cooperation. In this paper we present results from two UK-based studies that explore the identity dynamics of procedural justice theory. We reason that the police represent not only that the 'lawabiding, national citizen' superordinate group, but also a symbol of order/conflict and a range of connected social categories that can generate relational identification. First, we use a general population sample to show that relational identification with police, as well as identification as a 'law-abiding citizen', mediate some of association between procedural justice and legitimacy and are both stronger predictors of cooperation than legitimacy. Second, a sample of people living on the streets of London is used to explore these same relationships among a highly marginalised group for whom the police might represent a salient outgroup. We find that relational and superordinate identification are both strong positive predictors of cooperation, while legitimacy is not. These results have important implications for our understanding of both police legitimacy and public cooperation, as well as the extent to which police activity can serve to include — or exclude — members of the public.
\end{abstract}

Key words: procedural justice; police legitimacy; public cooperation; police; homeless people 


\section{Introduction}

In the UK, as in all democratic countries, the police rely on the willing cooperation of its citizens. The philosophy — or perhaps ideology — of British policing is premised on the idea of policing by consent, and there is widespread agreement within Government, the police and the public that securing and maintaining public respect and approval means also to secure the willing cooperation of the public in the task of helping police fight crime and observing laws (Home Office, 2012). Understanding why people will or will not cooperate with officers is thus critical if police are to fulfil their function in as an effective and ethical way as possible. When people voluntarily cooperate and comply, there is less of a need for coercion and excessive force, which, while intrinsic to the practice of police, is expensive in terms of resource and sometimes morally troubling in its application.

Yet, while this is true for all the 'publics' police serve, the question of consent is particularly important in marginalised communities, whose relations with police are often problematic, and where policing issues can be controversial and linked with conflict and/or accusations of illegitimacy ([authors anonymised], XXXXa). Such communities often have high levels of contact with police, and are sometimes marked by widespread victimization and offending. It is, for multiple reasons, especially problematic if willingness to cooperate with police is lowest in the communities where it is most needed.

In this paper we contribute empirically and theoretically to procedural justice theory (PJT). With its central focus on fairness, legitimacy, and identification between police and public, PJT has proven to be a popular model for understanding police-community relations. Existing research suggests that procedural justice is an important 'driver' of not just cooperation with the police but also compliance with laws and a wider set of 'self-regulatory' behaviors (Tyler, 2006). There are two well-established, complementary, mechanisms at work linking the experiences of fair process to cooperation (and unfairness to a lack of cooperation). One is about identification with the superordinate group that the police represent: people cooperate with authority figures who represent and embody positive social groups, which in the context of the police plausibly means "the law-abiding majority". The other is about perceptions of police legitimacy: people cooperate with legal officials representing an institution they believe has the right to power and authority to govern (i.e. that they find to be legitimate). Crucially, these two mechanisms are tied together through the internalization of group norms (Trinkner, 2019). When people identify with a particular group, they internalize its goals, values and motivations. A key part of this process is the recognition of the group's authority figures as an appropriate means to regulate behavior (Tyler, 1997) and produce mutually beneficial outcomes through cooperative behavior (Tyler \& Blader, 2000).

Yet, there are aspects of PJT that may limit its policy relevance when it comes to the policing of some of the marginalised groups with whom police have most contact. First, PJT research tends to focus on general population samples (e.g. Oliveira et al., 2020) and only infrequently on sub-populations such as minority group members, the socially excluded, or offenders. Of the 88 samples included in Walters and Bolger's (2019) recent meta-analysis of procedural justice, legitimacy and cooperation, only 12 covered populations that might be considered at least potentially marginal or socially excluded. Most of the latter were ethnic minority, immigrant or 'youth' populations (e.g. Murphy et al., 2015; Huq et al., 2011) and only a very few were offenders (e.g. White et al., 2016) or victims (Kochel et al., 2013). As such, we know much about how people in general understand and read policing (albeit the literature is surprisingly thin on a key part of PJT, see below), but we know rather less about whether general experiences replicate to those parts of the population who have most at stake in their interactions with officers, have sometimes long histories of problematic relations with police, and who are increasingly the focus of strategic priorities within policing (e.g. safeguarding, counter-radicalisation, anti-social behavior, and protest groups).

Second, there is a relatively limited police-focused literature addressing the nature and role of social identity and intergroup relations as mediators of fairness and legitimacy, cooperation and compliance (Radburn et al., 2016). Despite core aspects of PJT relying on social identity as an underlying psychological process, and despite group membership clearly being central to the dynamics of policecommunity relations in a wide range of contexts, there has been a comparative dearth of research that 
has tackled in depth this aspect of the theory (Radburn \& Stott, 2018) (for exceptions see e.g. Radburn et al., 2016; Murphy et al., 2015; Bradford, 2014). This has left the precise nature of the groups and categories in play under-specified and thus uncertain. Is it really plausible to suggest that the police only represent the 'law-abiding majority' - what Radburn \& Stott (2018: 427) call a 'relatively fixed and abstract superordinate category'? Might relational identification with the police as a distinct social group also play a role? Now more than ever, with social and political movements like Black Lives Matter and Blue Lines Matter having a strong public profile, it seems reasonable to assume that people can identity (or not) with the police in ways that are contested and contingent, even political-i.e. in ways similar to how they might identify with other social categories, such as particular political movements and groups.

In the UK context it is plausible to suggest that people view the police not only in terms of some superordinate group (the 'law-abiding majority') but also as a set of social categories in and of themselves. Relational identification (or lack of it) could be founded, for example, on extended encounters with police at public or sporting events; stem from a desire to 'protect the protectors' (as an on-going campaign run by the Police Federation - effectively the police union - asks people to do); be invested in the allure of traditional forms of order and authority; and/or be founded in the array of sentiments attached to Black Lives Matter. As Loader \& Mulcahy (2001: 39, italics in original) argue, lay dispositions disclose policing as a 'category of thought and affect' that is not only linked to narratives of social change, but also to 'the viability of the state and the security of its citizens' - to anxiety and hope, conflict and order. The police could represent not only the 'law-abiding majority' and traditional forms of authority, but also order/conflict and specific ingroups and/or outgroups.

In short, it is at yet unclear which group(s) and social categories police represent to people, and additionally whether the group dynamic aspects of PJT translate well into contexts where the policed are marginalised and excluded from the socially dominant categories usually associated with police. To help address these limitations, this paper presents a comparison between a general population sample and a group hitherto almost entirely absent from PJT research: people living on the streets. PJT is premised on the idea that compliance and cooperation with the police is motivated by relational concerns. But are these relevant for a group of people who are socially, economically and politically excluded? There is some early evidence that fair treatment, although important from an ethical perspective (treating people fairly is the "right thing to do"), is unlikely to motivate compliance in the street population context ([authors anonymised], XXXXa; [authors anonymised], XXXXb). However, relational concerns might still be important for promoting discretionary cooperation among this group (i.e., behaviors not mandated by law). People living on the streets often need to offend to survive, inhibiting the potential effect of relational concerns on compliance. But they also have relatively intense, or at least frequent, relationships with the police, because they are heavily policed. This may increase the salience of those relationships when it comes to discretionary behaviors such as cooperation and assistance.

Focusing on a particular, highly marginalized, population brings another benefit. All people adhere to multiple identities, any of which may be an important influence on how they experience police activity. Studies have considered, for example, whether strong identification with one's particular ethnic 'subgroup' moderates the association between procedural justice concerns and outcomes such as decision acceptance (Huo 2003), or whether 'defiant postures', likely to be strongly associated with particular group identities, might have a similar effect (Sargeant et al 2019). Yet, again, such research leaves the identities involved ill- and often undefined, limiting usefulness in terms of understanding the relationship between police and those real-life communities with whom they have most contact. This may be particularly important in cases where we might reasonably assume police constitute an outgroup for the policed. Comparing across our 'general' and 'street population' samples therefore allows us to consider the identity dynamics of PJT when (a) it makes sense that identification with the police might work within the broader category of identification with 'the law-abiding' (because for many British residents police are a culturally-loaded category/group representing order, stability and so on), but also (b) when police may instead, or also, comprise an outgroup (because homeless people are heavily 
policed and thus experience the police in a very different way to most others in society). Before proceeding to discuss the two studies that comprise this paper, we first provide a review of the literature on predictors of cooperation with the police.

A relational model of cooperation with the police: procedural justice, inclusion and legitimacy A wealth of PJT research has shown that fairness, especially fair process, is an important motivator of cooperation (Tyler, 1990; Tyler \& Blader, 2000; Sunshine \& Tyler, 2003). People are particularly attuned to four pillars of procedural fairness: treating people with fairness, dignity and respect; being transparent in their actions; providing citizens the opportunity for voice; and being impartial in their decision making. Importantly, evidence for this comes from studies demonstrating a positive link between procedural justice and cooperation among immigrants (Murphy et al., 2020), crime victims (Murphy \& Barkworth, 2014), and Muslim communities in the context of counter-terrorism policing (Madon, Murphy \& Cherney, 2016), as well as the general public (Murphy et al., 2008; Sunshine \& Tyler, 2003; Bradford, et al., 2015).

The central concern in this paper is why this is the case: why does procedural justice promote cooperation? Research has consistently shown that positive judgements across the criteria listed above are strong predictors of perceptions of police legitimacy (i.e., the extent to which policing is viewed as appropriate or 'rightful') (Tyler, 2006). In turn, legitimacy has been shown to be a key predictor of willingness to cooperate (Tyler \& Jackson, 2014). Existing work has linked fair and just police treatment to cooperation via increased perceptions of police legitimacy across different contexts and population groups (e.g. Sunshine \& Tyler, 2003; Tyler \& Huo, 2002; Murphy \& Cherney 2011, 2012; Mazerolle et al., 2013). Legitimacy might promote cooperation because it indicates a positive relationship with police and activates a reciprocal sense of duty toward them, premised for example on the idea that they are properly constituted authorities empowered to deal with issues of crime and disorder (Jackson et al., 2013).

Our main interest, however, is in the other mechanism thought to link procedural justice to legitimacy: social identity (Tyler, 1990, 2006). Research utilizing PJT has adopted early iterations of social psychological theories of social identity (Tajfel \& Turner, 1979) to explain the relationship between procedural justice and cooperation. A small number of studies have assessed the links between procedural justice, identification with police and associated social categories, and outcomes such as cooperation and compliance (Bradford et al., 2015; Radburn et al., 2016; Murphy et al., 2015). The assumption is that police behavior carries important identity relevant information: police officers, through the way they treat those they encounter, communicate messages concerning inclusion, status and value within the social category or categories the police are thought to represent, categories which are usually conceptualised and operationalized in terms of national, community or citizenship identities (Bradford, 2014). PJT suggests that judgements about the fairness of the police will be the most important factor in such a process. As theorized by the Group Engagement Model of procedural justice (GEM), fairness promotes a sense of inclusion and value, while unfairness communicates denigration and exclusion (Blader \& Tyler, 2009; Tyler \& Blader, 2003). Positive social identities in relation to the police should on this account promote cooperation (Bradford, 2014).

Moreover, it is argued that legitimacy reflects a normative alignment between an individual's values and the group's values, whereby one accepts the duties, responsibilities and shared goals attached to group membership (Huq et al., 2017); and several recent studies have treated identity as a potential antecedent of legitimacy (Bradford 2014; Bradford et al., 2014). On this account, stronger social ties with groups associated with police motivates legitimation of the police as important group representatives. Such identification promotes a sense of moral congruence that flows from perceptions of shared group membership, and the internalization of the values and goals of the group, which, in the case of policing, seem likely to include 'fighting crime' and dealing with disorder (Tyler and Huo 20021 Tyler 2011). Social identity, therefore, may mediate the association between procedural justice and legitimacy.

More recently, studies have begun to explore the extent to which the relational aspects of procedural 
justice have what might be characterized as a more direct effect on people's self-categorization, promoting identification not with superordinate categories they may or may not share with police, but with the latter as a distinct social group in and of itself (Radburn et al., 2016; Murphy et al., 2020). This line of work stresses the contingent nature of the relationships between police and public, and that the bonds formed and shaped by procedural justice refer not only, or even primarily, to 'fixed' and distant categories such as nation, state or 'lawfulness'. Rather, social bonds between police and policed are formed in situ, during interactions, and reference a direct relationship between the two (or its absence) (Radburn \& Stott 2018). On this account, procedural justice promotes cooperation when and to the extent it promotes a sense of identification with police themselves, in tandem with or in distinction from the superordinate group that the police represent.

Moreover, in some contexts, the police become an oppositional group for certain members of the public that diminishes the salience of or even decouples from the superordinate group (the 'law-abiding majority'). For example, in the context of the policing of crowd events, Radburn et al. (2016) observed that judgements of the same policing incident varied according to social categorization. The same police action was judged to be more fair when people believed it was directed towards a group socially distant from themselves, and less fair when the group involved was socially closer to them: it was participants' relational identification with the police, vis a vis the group against which police were taking action, that shaped their judgements of the fairness of police activity.

People may, then, identify with the police as a distinct social group rather than a superordinate category per se, and such identification may be a potentially important psychological mediator of procedural justice. Work across different contexts and population groups has linked police procedural justice to cooperation via both increased identification with the police as a distinct social category (e.g. Radburn et al., 2016) and increased identification with superordinate social categories such as nation or community (Huo, 2003; Bradford, 2014; Bradford et al., 2015; Bradford et al., 2014; Madon et al., 2016; Sargeant, et al., 2016). Yet, few if any studies have considered both at the same time (see Murphy et al., 2020 for an exception). Studies linking procedural justice to identification with superordinate social categories may thus be capturing the association between procedural justice and identification with police, and vice versa. Or it could be that parallel processes are in play, where both forms of identification play a role.

Neither mediating pathway has yet been investigated among members of a social group as socially excluded as the street population. One interpretation of the Group Value Model of procedural justice (GVM; Lind \& Tyler, 1988) would be that procedural justice should be less important to people from highly marginal social groups because, in a sense, their position vis a vis the police has already been determined. Officer fairness becomes less salient to people - their relationship with the police less identity relevant - when there seems little doubt that they do not belong in the group(s) the police represent (Murphy et al., 2015). If this is the case then it would render particularly problematic the idea that police activity can serve to make homeless people feel included in superordinate social categories or simply 'society', since they would seem a priori already excluded. It would also have important implications in terms, for example, of police efforts to work with partners in ways that promote processes of social inclusion among marginalized groups, rendering them, at the very least, more difficult than would otherwise be the case.

However, we hypothesize that police procedural justice will be important for the street population, as well as the general public (a notion more in line with the Group Engagement Mode of procedural justice - Blader and Tyler 2009). A plausible explanation for this is that precisely because homeless people can feel socially disconnected and marginalized (Belcher \& DeForge, 2012) they have 'skin in the game' - they are aware of their unfavourable position, dislike it (on average), and are therefore especially attuned to signals from police and other authorities that indicate they are in fact accepted and worthy members of society. If this is the case, procedural justice should promote homeless people's identification with the police and the social categories they represent in a way similar to its apparent effect within general population samples, which will in turn activate a desire to do right by those that share those identities (i.e. cooperate with officers). 
Research on ethnic minority groups, young people and others tends to support this idea. The metaanalysis conducted by Walters and Bolger (2019) suggested that the association between procedural justice and cooperation was stronger for younger people and those from minority groups, for example. Work outside the PJT paradigm also suggests that even when individuals are in highly marginal social locations they are sensitive to identity-relevant communication from authorities and power-holders. Studies of desistence from crime, for example, have found that 'negative' (labelling) or 'positive' (delabeling) behaviors and messaging from authorities can inhibit or promote desistence via their effects on the identities of offenders (Maruna et al., 2004).

A further issue here is that little is known about how other identities, beyond superordinate categories defined by citizenship and nationality, on the one hand, and relational identification with police, on the other, affect and interact with the processes described above. People identify with a wide range of categories, and some of these - most obviously racial or ethnic identities - may imply particular views of or relations with police. As noted, some work has indeed considered the role of ethnic identification in people's relations with police (Huo 2003; Murphy and Cherney 2011; Walters and Bolger 2019). In all such studies, however, ethnic identification is treated as sui generis, formed independently of relations with police, rather than as something formed in particular institutional contexts of which, of course, the police are part. This may be particularly important in the current context because homeless people living in London have a lot of contact with police, meaning that their sense of self - as, for example, members of the homeless 'community' - may be shaped by officers' actions in ways that go beyond the ideas superordinate identification and relational identification outlined above. One obvious possibility is that the experience of police unfairness triggers a tightening of group boundaries, and consequently stronger identification with the homeless ingroup, which inhibits the propensity to cooperate with police who are correspondingly more clearly an oppositional outgroup (c.f. Stott et al., 2012).

There is, of course, disagreement within the field regarding the concepts and causal relationships within the process-based model of policing described by PJT; for example, the extent to which procedural justice, trust, identification and legitimacy are separate constructs (Tyler, 2006; Jonathan-Zamir et al., 2015), the extent to which the relationships between these constructs are causal (Nagin and Telep, 2020), the measurement and operational definitions of key terms within this framework (Tankebe, 2013), and the lack of adequate attention to the social and cultural context within which this framework operates (Tankebe, 2009). But our decision to treat procedural justice, legitimacy and identification as distinct theoretical constructs is not new-this approach has been supported in a plethora of observational, experimental and other forms of empirical and indeed theoretical study (e.g. Jackson et al. 2012; Jackson \& Gau 2016; Bradford et al. 2015; Hamm et al 2017). We therefore proceed on the basis that these are separate constructs (see results section below), and that we need to better specify the relationship between them. That is, we take a conceptual (a priori) modelling approach to form the constructs of police identification and normative alignment that we use in our analyses, and rely on the model fit of the measurement models as indicators that these are indeed capturing separate constructs. If police identification and normative alignment form empirically distinct latent constructs, we will model them as police identification predicting normative alignment, reflecting that the idea that when people see the police as "us", they tend to see the police as enacting and defending some salient group values and norms.

\section{Understanding how identification and legitimacy motivate cooperation}

While processes of identification seem to work in conjunction with legitimacy judgements to promote cooperation with police, few studies have explicitly modelled the relationship between identity and legitimacy as mediators of the association between procedural justice and cooperation, and few studies have considered in detail how the motivational power(s) of identification and legitimacy work in conjunction with one another (for exceptions see e.g. Murphy \& Cherney, 2011, Bradford, 2014). Building on the discussion above, there are at least five ways in which processes of identification and legitimation might shape people's willingness to cooperate with police, all of which provide potential mechanisms linking procedural justice to cooperation: 
i) People who identify with the police as a specific social category may be more willing to cooperate because they feel a sense of shared group membership and duty towards other group members (i.e. police officers).

ii) People who identify with the superordinate group that police represent may be more willing to cooperate because they feel a sense of shared group membership with police and/or a sense of duty towards the wider group.

iii) People who identify more strongly with particular subgroups distinct from the police and what they represent - here, 'the homeless community' - may be less willing to cooperate because they see police as an oppositional outgroup.

iv) Those who grant the police more legitimacy may be more willing to cooperate because legitimacy involves reciprocal relationships - we may feel we have a duty to support authorities we judge as legitimate, for example - implying a direct path between legitimacy and cooperation.

v) People who identify with the police as a specific social category and/or with the superordinate group(s) police represent may grant the police more legitimacy and be more willing to cooperate on that basis - legitimacy may mediate some or all of the association between identification and cooperation.

\section{The present studies}

We focus our efforts on understanding how procedurally just policing motivates discretionary cooperation with the police. To be clear at the outset, we are not proposing that one or a few of the above relationships will necessarily predominate in any one context or across different contexts. All are plausible, and all find some support in existing literatures. Rather, we seek to test them jointly, in the specific context of British policing. In Study 1 we use a general population sample to test the pathways toward cooperation outlined above. In Study 2 we hone in on those that seem most important and salient to a consideration of PJT in the context of homelessness, and explore how they play out among a population living in a context of extreme marginalisation. A key question underlying this paper is whether the processes proposed to mediate the relationship between procedural justice and cooperation-legitimacy and social identity - work in the same ways for the street population as they do for the general public.

We propose that the social psychology of homeless people will be similar to that of the general public when it comes to discretionary forms of cooperation, such that procedural justice is linked to cooperation via identification with the social categories the police represent and perceptions of police legitimacy. We test this proposition using survey data collected from 200 people living on the streets of London; and compare people living on the streets of London to a general population sample of 509 residents of England, Scotland, and Wales.

We opted to present our findings as two separate studies because data were collected at different times, in different ways, and from such different populations that a multiple group model analysis (split between the street population sample and the general population sample) did not seem an appropriate way to compare the two groups. Some item wordings also varied between the two surveys. We proceed, first, with the general population sample.

\section{Study 1}

\section{Method}

\section{Participants and design}

Participants were 509 residents of England, Scotland, and Wales, recruited via the online platform Prolific. Prolific is similar to other crowdsourcing platforms, such as Mechanical Turk, but has a larger, more diverse pool of UK participants. Data were collected on July 31, 2018. Participants were generally representative of the UK population on age, gender, and ethnicity (ONS 2017, see Table 1 for sample characteristics). $50 \%$ of participants were male, $40 \%$ were aged between $25-44$ (39\% 45-64, 11\% 18$24,10 \% 65+), 87 \%$ were white British (6\% Asian or Asian British, $4 \%$ mixed background, $3 \%$ black 
or black British, and $1 \%$ other ethnic group), and $88 \%$ of participants were born in the UK. Participants were paid $£ 1.80$ for taking part in the study.

The dataset used for our analysis comes from an experimental study of responses to armed police in Great Britain (Yesberg, Bradford \& Dawson, 2020). However, the data included similar measures to those reported in Study 2, and so are well served for our purpose of comparing the street population to the general population. Specifically, participants were asked a series of questions about procedural fairness, their willingness to trust and grant legitimacy to the police, identification, and cooperation. Note that these questions were asked at the start of the Yesberg et al. (2020) study and therefore participants' responses were unlikely to have been affected by the nature of the study.

\section{Measures $^{1}$}

Procedural justice. Police procedural justice was measured using two items: The police explain their decisions to the people they deal with; The police would treat you with respect if you had contact with them for any reason ( 2 items from Jackson et al.'s 2020 procedural justice scale).

Legitimacy. Scholars typically, but not universally, define legitimacy along two connected lines: (a) the perceived right to power and (b) the sense of 'willing consent' that flows from such an ascribed quality (people feel a duty to obey officers when they view the institution as moral, just and appropriate). Following UK work (Huq et al., 2017), we operationalise the first part of the legitimacy construct (perceived right to power) as normative alignment (the belief that officers act in normatively appropriate ways, and thus have the right to power) rather than institutional trust (the belief that officers can be trusted to act in ways that take into account the interests of citizens, and thus have the right to power). For discussion, see Jackson \& Gau (2016) and Jackson (2018). Normative alignment was measured using three items (Posch et al., 2020): The police can be trusted to make the right decisions; The police usually act in ways that are consistent with my own ideas about what is right and wrong; The police stand up for moral values that are important for people like me.

Also following UK work, we operationalise the second part of the legitimacy construct (a sense of 'willing consent') as moral duty to obey (for discussion, see Bottoms \& Tankebe, 2012; Tyler \& Jackson, 2013; Posch et al., 2020). Duty to obey was also measured using three items (Trinkner et al., 2018): It is my moral duty to back the decisions made by the police because the police are legitimate authorities; It is my moral duty to support the decisions of police officers, even if I disagree with them; It is my moral duty to do what the police tell me even if I don't understand or agree with the reasons.

Identification. Police identification was measured using three items (Radburn et al., 2016): I identify with the police; I feel a sense of solidarity with the police; I feel similar to the police. Superordinate identification (with a group the police can plausibly be said to represent, the 'lawabiding'), was measured using two items (Bradford et al., 2015): I see myself as an honest, law-abiding citizen; It is important to me that others see me as an honest, law-abiding citizen.

Cooperation. Cooperation with the police was measured using three items (Jackson et al., 2013): If the situation arose I would call the police to report a crime I witnessed; If the situation arose I would report suspicious activity near my house to the police; If the situation arose I would provide information to the police to help find a suspected criminal.

Demographics. Participants reported their gender (male/ female), age (4 age bands), ethnicity ( 6 choices), and country of birth (UK/non-UK).

\section{Analysis plan}

To assess scaling properties, we first tested the factorial structure of the latent variables by specifying a measurement model using confirmatory factor analysis (CFA) in MPlus 8. The relationships between these were then investigated using structural equation modelling (SEM) in MPlus 8.

\footnotetext{
${ }^{1}$ See Appendix for a list of the items used. Factor loadings and model fit for the CFA are also provided.
} 


\section{Results}

\section{CFA measurement model}

We tested the fit of a measurement model that included five covarying latent constructs of police procedural fairness, legitimacy (normative alignment and duty to obey), police identification, superordinate identification, and cooperation. CFA results are presented in the Appendix. The model produced acceptable fit indices (Chi-Square $=455, \mathrm{df}=94, p<.001$; RMSEA $=.086[.078, .094]$; CFI $=.980 ; \mathrm{TLI}=.974)$, with all standardized factor loadings $>.7 .^{2} \mathrm{We}$ then use this model as the basis for answering our questions using structural equation modelling (SEM). Covariances between latent constructs are presented in Table 2.

\section{Structural equation modelling}

We used MPlus 8 to fit a structural model that investigated direct and indirect pathways from police procedural fairness, to the two forms of identification (relational and superordinate), to legitimacy, to cooperation. SEM accounts for measurement error by partitioning the variance of each factor into measurement error and shared variance. The model included police procedural fairness as the predictor variable on the far left-hand side of the model (Figure 1 presents the specified direct and indirect paths of the model), the two forms of identification (which were allowed to covary in the model), legitimacy as a potentially mediating variable, and cooperation as the outcome variable. All latent variables in the model were regressed on gender, age, ethnicity, and country of birth. The fitted model, with controls, produced fit indices of similar adequacy to the measurement model (Chi-Square $=500, \mathrm{df}=161$, $p<.001$; RMSEA $=.064[.058, .071]$; CFI $=.981 ;$ TLI $=.974)$. We present standardized regression coefficients for all paths in Table 3.

The various predictors in the model explained $6 \%$ of the variance in police procedural justice (via the control variables not shown in the figure and table), $45 \%$ of the variance in police identification, $22 \%$ of the variance in superordinate identification, $64 \%$ of the variance in legitimacy, and $42 \%$ of the variance in cooperation.

The fitted model is consistent with the idea that identification with police, as well as with a superordinate category they can reasonably be said to represent ('the law-abiding'), mediates the observed associations between procedural justice and both legitimacy and cooperation. Police procedural fairness was associated with higher levels of police identification $(\beta=.64, p<.001)$, superordinate identification $(\beta=.31, \mathrm{p}<.001)$, and legitimacy $(\beta=.26, \mathrm{p}<.001)$. In other words, in line with existing PJT work, the more procedurally just respondents perceived the police to be, the more strongly they tended to identify with these two social categories, and the more legitimacy they tended to invest in the police. In turn, police identification positively predicted legitimacy $(\beta=.44, p<.001)$ and cooperation $(\beta=.32, p<.001)$. Superordinate identification also positively predicted legitimacy $(\beta=.26$, $\mathrm{p}<.001)$ and cooperation $(\beta=.27, \mathrm{p}<.001)$. Finally, legitimacy positively predicted cooperation $(\beta=.16$, $\mathrm{p}<.001)$.

Note that as specified the model does not contain a direct path from procedural justice to cooperation. When this was allowed in a separate model (results not shown here) it was non-significant $(p=.66)$, so we proceeded with the more parsimonious model. The frequently identified association between procedural justice and willingness to cooperate with the police was in this sample entirely mediated by the variables shown in the model (Table 3); the combined indirect statistical effects of procedural justice was statistically significant and substantively large $(\beta=.37, \mathrm{p}<.001)$, with around half of this going via

\footnotetext{
${ }^{2}$ We also ran a CFA that specified normative alignment and relational identification as one latent construct and obligation to obey as a second latent construct. The fit statistics were not as good (Chi-Square $=899, \mathrm{df}=94, p<.001 ; \mathrm{RMSEA}=.130[.122$, $.137]$; CFI $=.954$; TLI $=.941$ ). The correlation between normative alignment and relational identification as one latent construct and obligation to obey as a second latent construct was 0.84 . When we combined relational and subordinate identification into one latent construct (and kept legitimacy as both normative alignment and obligation to obey), the fit statistics were also not as good (Chi-Square $=635, \mathrm{df}=98, p<.001 ; \mathrm{RMSEA}=.104[.096, .112] ; \mathrm{CFI}=.969 ; \mathrm{TLI}=.962)$. The standardized factors loadings for the two superordinate identification indicators were less than $0.70(0.64$ and 0.50 respectively).
} 
the procedural justice to police identification to cooperation pathway $(\beta=.19, \mathrm{p}<.001)$, and around of quarter going via the procedural justice to superordinate identification to cooperation pathway $(\beta=.08$ $\mathrm{p}<.01)$, Note also the relative weights of the association between procedural justice and the identity measures, on the one hand $(\beta=.64$ and $\beta=.31)$, and legitimacy, on the other $(\beta=.27)$. Among this sample, at least, police identification and superordinate identification were both more strongly predicted by procedural justice than was legitimacy.

It is noticeable that the strongest indirect pathway from procedural justice to cooperation went through police identification (Table 3). This is consistent with the idea that procedural justice motivates cooperation in part by encouraging citizens to identification with the social category of the police. Prior research has shown that procedural justice has an empowering and/or power equalising quality, with the experience of procedural justice decreasing people's sense of power distance regarding the police (Mentovich, 2012; Posch et al., 2020). Procedural injustice has also been linked to feeling like the police treat one as an object of suspicion, as a potential criminal (Tyler et al., 2015; cf. Jackson et al., 2021). In our study, it may be that procedural justice is associated with lower oppositional dynamics, making police a more positive social category in the eyes of observers.

\section{Summary}

Notwithstanding the typical limitations associated with online survey participants (Wright, 2005), we used a general population sample to show that identification with police, as well as with a superordinate category they can reasonably be said to represent ('the law-abiding'), mediates the associations between procedural justice, legitimacy and cooperation. We showed that the pathway between procedural justice and cooperation may be more complicated than is often proposed. Perhaps what is most striking from the model shown above is the multiple ways in which procedural justice seems to explaining variation in cooperation - through identification with the police, with an identity they represent, and legitimacy.

Like many existing studies that have empirically addressed the role that social identity processes might have in relation to public perceptions of the police and policing (Tyler and Huo 2002; Huo 2003; Murphy and Cherney 2011; Murphy 2013; Bradford 2014; Bradford et al., 2014; Bradford et al., 2015; Madon et al., 2016), the focus of Study 1 was on relatively fixed and abstracted social identities and on a general population sample. In Study 2 we hone in on the identity dynamics of policing among a street population sample where one might imagine that the same patterns do not apply, and assess the ways in which procedural justice impacts on cooperation for this group. While we do not know which social categories were underpinning relational identification with the police, it does seem like it is playing a role that is separate to the more traditional superordinate identification that prior work has examined.

Motivating Study 2 is the current lack of understanding of how the PJT process may operate in relation to other forms of identity among marginalised communities. While a range of studies have empirically addressed the precise impact that social identity processes have in relation to public perceptions of the police and policing (Tyler \& Huo 2002; Huo 2003; Sunshine \& Tyler 2003; Murphy \& Cherney 2011; Murphy 2013; Bradford 2014; Bradford et al., 2014; Bradford et al., 2015; Madon et al., 2016) their focus has tended to be on relatively fixed or abstracted social identities such as 'community', 'nationality', 'citizenship' or 'ethnic minority status'. Largely missing is investigation of how the PJT 'process' may operate in relation to specific forms of identity among marginalised populations. Considering the particular group at hand, then, we also add the extent to which they identity with and as the category 'homeless' to the equation. Moreover, this is a group that experiences high levels of contact with the police, and who often have personal relationships with officers ([authors anonymised]; XXXXa). Considering that legitimacy is about a formal relationship with power, this salience, to the homeless, of police officers as people as well as representatives of superordinate social categories with the power to include and exclude, might alter the way that identity judgements and legitimacy judgements motivate cooperation with the police.

\section{Study 2}




\section{Participants and design}

Homeless people $(\mathrm{N}=200)$ were recruited on the streets of an inner London borough solely on the basis of their willingness to participate. The first author collected the data between February and March 2020 at various soup kitchens - outdoor places where food was served to homeless people - spread across this inner London borough. We set out to achieve 200 participants, the typical recommended sample size for structural equation modeling (SEM) analyzing models of average complexity (Kline, 2011). We are confident that our study is sufficiently powered because two simulation studies recommended even smaller sample sizes for SEM models of similar complexity to that we report in this paper (Wolf et al., 2013; Sideridis et al., 2014). We conducted an ad-hoc power analysis (using G*Power) given study 2's $\alpha$ (.05), sample size (200), and effect size (.96 - given the $\mathrm{R}^{2}$ value of the 'cooperation' outcome variable) to determine whether our sample size was suitably powered for study 2 . Results confirmed that our sample size was suitably powered for study 2 ( $92 \%$ power).

Some $87 \%$ of participants were male, $49 \%$ were aged between $45-64$ (48\% 25-44, 3\% 18-24, 1\% 65+), $37 \%$ were white British (33\% white other, $14 \%$ black or black British, $8 \%$ mixed background, $6 \%$ other ethnic group, 3\% Asian or Asian British). 57\% were born in the UK, and 54\% had lived in the UK all their life (34\% 5-10 years, 12\% 2-5 years, $1 \% 1-2$ years). We are confident that most, if not all, participants actually lived on the streets at the time of data collection because (a) they were recruited at soup kitchens that specifically targeted people living on the streets, (b) most participants carried around evidence that they were rough sleeping (e.g. sleeping bags and blankets), and (c) all participants selfreported that they were rough sleeping in their survey responses $-52 \%$ had been rough sleeping for 6 months- 1 year, $22 \% 1-2$ years, $15 \% 1-3$ months, $11 \%$ 3-6 months, $1 \%$ less than a month and $1 \%$ more than 2 years.

A single questionnaire booklet that included items assessing perceptions of the police in London, social identification and cooperation behaviors was distributed to homeless people on the street. The first author was present throughout the entire process, and provided help or support as required while also allowing respondents 'space' to complete the forms themselves. The questionnaire booklet was made up of 4 sections: Section 1 used adapted versions of published and validated measures to assess attitudes towards the police. Section 2 used published and validated measures that assess cooperation behaviors. Section 3 used established measures of social identification adapted to measure homeless identification, police identification, and superordinate identification. Section 4 asked participants to report demographic information, and their homeless/ migrant status.

Informed consent was obtained from all participants. The questionnaire booklet took approximately 10 minutes to complete, and participants received $£ 5$ compensation for their time. The research was approved by the ethical review board at UCL $(15985 / 001)$.

\section{Measures $^{3}$}

All items were answered on a 1-5 (disagree-agree) scale unless otherwise indicated.

Police procedural justice. Police procedural justice was measured using three items (e.g. The police treat people with respect; 3 items from Jackson \& Bradford's 2019 procedural justice scale).

Police legitimacy. Perceived police legitimacy was again operationalized as normative alignment and duty to obey (Jackson et al., 2012; Bradford \& Jackson, 2018). Duty to obey was measured using three items (e.g. I feel a moral obligation to obey the police; Trinkner et al., 2018), and normative alignment was measured using three items (e.g. I support the way the police usually act; Trinkner et al., 2018).

Cooperation. Willingness to cooperate with the police was measured using two items (I would help the police if asked, e.g. identify someone wanted of a crime if I could help; two items from Jackson et al.'s, 2020 cooperation scale).

\footnotetext{
${ }^{3}$ See Appendix for a list of the items used. Factor loadings and model fit for the CFA are also provided.
} 
Identification. Relational identification with the police was measured using three items (e.g. I feel a sense of solidarity with the police; Radburn et al., 2016 relational identification with the police scale); and superordinate identification was measured using two items (e.g. I see myself as an honest, law-abiding citizen; Bradford et al., 2015 superordinate identification scale). Homeless identification was measured using 10 items, that measured five dimensions of homeless identification (Leach et al.'s, 2008 social identification scale): two items measured identity solidarity (e.g. I feel a bond with other homeless people), two items measured identity satisfaction (e.g. I think that homeless people have a lot to be proud of), two items measured identity centrality (e.g. I often think about the fact that I am homeless), two items measured self-stereotyping (e.g. I am similar to the average homeless person), and two items measured in-group homogeneity (e.g. Homeless people are very similar to each other).

Demographics and homeless/ migration status. Participants reported their gender (male/ female), age (4 age bands), and ethnicity ( 6 choices). They were also asked to indicate whether they were born in the UK (yes/ no), time spent in the UK (1-6 scale (less than a year - all my life)), and time they have been homeless (1-6 scale (less than a month - more than 2 years)).

\begin{abstract}
Analysis plan
In order to validate our measures, we first tested the factorial structure of the latent variables by specifying a measurement model using confirmatory factor analysis (CFA) in MPlus 8. The relationships between these were then investigated using structural equation modelling (SEM) in MPlus 8 .
\end{abstract}

\title{
CFA measurement model
}

\section{Results}

We tested whether a measurement model that included six covarying latent constructs of police procedural fairness, legitimacy ${ }^{4}$, police identification, superordinate identification, homeless identification, and cooperation fitted the data well. CFA results are presented in Appendix A. This model produced acceptable fit indices according to CFI and TLI, but not according to RMSEA (ChiSquare $=876.9, \mathrm{df}=284, p=<.001 ; \mathrm{RMSEA}=.103[.095, .111] ; \mathrm{CFI}=.966 ; \mathrm{TLI}=.962)$. We therefore followed modification indices and added, for the homeless identification latent construct, two within factor covariances (two covariances between homeless identification items: 'I feel a bond with other homeless people' was allowed to covary with 'I feel solidarity with other homeless people'; and 'Homeless people have a lot in common with each other' was allowed to covary with 'Homeless people are very similar to each other'). Conceptually it made sense to include these two particular covariances in the model because the item couples measure different facets of identification respectively ( 2 items measure identity solidarity, and 2 items measure in-group homogeneity, whereas all other items do not, according to Leach et al., 2008). This respecified model provided an adequate fit to the data (Chi-Square $=616.5, \mathrm{df}=282, p=<.001 ; \mathrm{RMSEA}=.078[.069, .086] ; \mathrm{CFI}=.981 ; \mathrm{TLI}=.978)$ with all standardized factor loadings $>.8$. We use the respecified model as the basis for answering our questions using structural equation modelling (SEM).

\section{Descriptive statistics}

Descriptive statistics and correlations between latent constructs are presented in Table 4. Importantly, although mean levels of police procedural justice, police legitimacy, and cooperation were not significantly higher/ lower than the mid-point of 3 on the 5-point scales, all three types of identification were, such that the street population, on average, identified relatively strongly as homeless $(\mathrm{t}(199)=$ $6.31, \mathrm{p}<.001)$, but identified relatively weakly with the police $(\mathrm{t}(199)=-6.58, \mathrm{p}<.001)$.

\section{Structural equation modelling}

\footnotetext{
${ }^{4}$ Differences were negligible comparing the approximate fit statistics between a measurement model that combined normative alignment and duty to obey into one 'legitimacy' latent construct and a measurement model that differentiated normative alignment and duty to obey as two separate constructs, but the two components of legitimacy were so highly correlated that it made little sense to differentiate between them and caused problems in the model. We thus opted for the one latent construct of legitimacy for a simpler analytical model.
} 
We used MPlus 8 to specify a structural model that investigated direct and indirect pathways from police procedural fairness, to the three forms of identification, to legitimacy, to cooperation. The model included police procedural fairness as the predictor variable, the three forms of identification (which were allowed to covary in the model to take account for any confounding non-measurable variance) and legitimacy as the mediating variables, and cooperation as the outcome variable. All latent variables in the model were regressed on gender, age, ethnicity, UK born, time in the UK, and time homeless. This model, with these controls, produced fit indices of similar adequacy to the measurement model $($ Chi-Square $=728 \mathrm{df}=402, p=<.001 ;$ RMSEA $=.064[.057, .072] ; \mathrm{CFI}=.981 ; \mathrm{TLI}=.977) . \mathrm{We}$ present the specified direct and indirect paths of the model in Figure 2. We present standardized regression coefficients for all paths in Table $5^{5}$.

The various predictors in the model explained $13 \%$ of the variance in police procedural justice (via the control variables not shown in the figure and table; $\mathrm{R}^{2}=.13$ ), $40 \%$ of the variance in police identification $\left(\mathrm{R}^{2}=.40\right), 23 \%$ of the variance in superordinate identification $\left(\mathrm{R}^{2}=.23\right)$, and $6 \%$ of the variance in homeless identification $\left(\mathrm{R}^{2}=.06\right)$. Police procedural fairness was associated with increased homeless identification, police identification and superordinate identification. In other words, the more procedurally just members of the street population perceived the police to be, the more strongly they identified with these three social categories.

The model explained $74 \%$ of the variance in legitimacy $\left(\mathrm{R}^{2}=.74\right)$. Police procedural fairness predicted perceptions of police legitimacy $(\beta=.65, \mathrm{p}<.001)$. Homeless identification and superordinate identification did not have an association with perceptions of police legitimacy; however, police identification positively predicted perceptions of police legitimacy $(\beta=.26, p<.001)$. In fact, police identification partly mediated the positive relationship between police procedural justice and perceptions of police legitimacy $(\beta=.14, \mathrm{p}<.001)$.

The model explained $49 \%$ of the variance in cooperation $\left(\mathrm{R}^{2}=.49\right)$. For members of the street population, fair treatment and police legitimacy did not have any direct effect on their willingness to cooperate. The only significant predictors of cooperation were police identification $(\beta=.28, \mathrm{p}<.05)$ and superordinate identification $(\beta=.32, \mathrm{p}<.001)$. In fact, any association between police procedural fairness and cooperation was completely mediated by identification (police $(\beta=.15, \mathrm{p}<.05)$ and superordinate identification $(\beta=.15, \mathrm{p}<.05))$, but not police legitimacy.

\section{Robustness checks}

Despite our sample size justification above, to increase our confidence in our SEM model's results even more, and mitigate any concerns regarding statistical power given our sample size, we also (a) fitted the same model without specifying any indirect effects, (b) fitted ordinal regression models to the outcome variables using SPSS, and (c) did path analysis of the same model using manifest indicators (saved component scores from Principle Components Analysis). The results remained the same.

\section{Summary}

Our findings reveal a simple story: police procedural justice is related to willingness to cooperate with the police among members of the street population but only to the extent that they identify with the groups that the police represent. Perceptions of police legitimacy were not related to cooperation.

\section{Discussion: implications for theory and practice}

In this paper we have presented results from two UK-based studies that explored the identity dynamics of procedural justice theory (PJT), first among a general population sample, and then among a highly marginalized group: namely, those living on the streets of London. We used the general population sample to show that relational identification with police, as well as with a superordinate category they can reasonably be said to represent ('the law-abiding'), seems to mediate the associations between procedural justice and cooperation, as does legitimacy. Turning to the sample of homeless people, we

\footnotetext{
${ }^{5}$ For the sake of a direct comparison to the general population model, we also ran this SEM model without homeless identification in it, and the results remain the same.
} 
found that identification with the social categories associated with police ('the police' and 'the law abiding') seems to mediate the association between procedural justice and cooperation, and that perceived police legitimacy did not predict cooperation (and therefore played no mediating role). Perhaps surprisingly, another identity potentially important to this group as homeless people also seemed to play little if any role.

Overall, our findings suggest that the pathway between procedural justice and cooperation may be more complicated than is often assumed. Consistent with classical PJT theorising (Tyler \& Blader, 2000), process mattered: to the extent that the general public perceived the police interacted with people in a fair and respectful manner, they were more likely to report legitimacy and cooperation. But there may be multiple ways in which procedural justice can promote cooperation, through relational identification with the police, with a superordinate identity they represent, and legitimacy. To put it another way, legitimacy and different aspects of identification, do not, when measured separately, seem to stand as proxies for one another, but rather each makes a unique contribution to explaining the link between procedural justice and cooperation.

We also examined whether process mattered among the street population, a highly marginalized group. We showed that police procedural justice predicted willingness to cooperate among members of the street population but only to the extent that they identified with the police and as the 'law-abiding'. The homeless identity was not associated with cooperation, but it was associated with procedural justice. Although the positive effects of procedural justice on police (Radburn et al., 2016), and superordinate identification (Bradford et al. 214) are in line with existing PJT work, the positive association between procedural justice and homeless identification might come as a surprise. Our post hoc hypothesis here is that fair treatment by the police may signal to members of the street population that they are worthy of fair treatment 'as they are', and so they might identify more strongly with that sense of self (homeless) as a result. By contrast, they may neglect or deny a homeless identity when they experience unfair treatment they feel results from membership of that very category. This finding speaks to, and provides evidence for, an under-examined assumption in procedural justice theory - that police represent a social group that is meaningful even to the often marginalised people with whom they interact.

Unlike with the general population sample, and existing PJT research, perceptions of police legitimacy were not associated with cooperation among our sample of homeless people. One explanation for this may be found in consideration that legitimacy concerns a broadly formal relationship with power, and with the institution of police (Hawdon, 2008). Members of the street population, however, have a more personal relationship with police than most people, because they interact with officers very much more frequently (something that was borne out of [authors anonymised] (XXXXa) qualitative study). The salience, to the homeless, of police officers as people, as well as representatives of superordinate social categories with the power to include and exclude, may help explain the greater importance of identity judgements vis a vis legitimacy, in Study 2. That is not to say that legitimate relations between police and homeless are not important, but that they are superseded, in this instance, by other factors.

A central message from the current paper is therefore that, despite their extreme marginality, the sources of cooperative behaviour among the street population may be broadly similar to those among the larger population from which they are drawn. Our findings thus have important implications for understanding both police legitimacy and public cooperation, and the extent to which police activity can serve to include - or exclude. Efforts, premised in PJT, to improve or protect the relationship of the police and the public are likely to be effective, even when the latter are excluded in multiple ways. More interesting, though, are our results regarding social identification for both the general population and the street population. In particular, it seems that procedurally just police activity may be able to foster homeless people's identification with the police, with an identity they represent (the 'law abiding'), and with the associated norms and values of those identities, as well as make them feel worthy of fair treatment while maintaining their 'homeless' sense of self. This highlights the value of police adopting process-based policing styles to promote inclusion for this stigmatized population, many of whom distrust police and feel targeted for 'special' attention ([authors anonymised], XXXXa). Like many 
others, we would argue that it is important for police officers to treat homeless people with respect and dignity. They should do this because it is the right thing to do - but also because it will help to promote cooperation and, moreover, may serve to foster a stronger sense of social inclusion among this group (or, at least, avoid further stigmatization). This is important not because procedural justice is a 'magic wand' that can improve the lives of homeless people on its own. Indeed, this could not be the case, given the material conditions in which they live. However, policing conducted in this mode may form a useful adjunct to larger efforts to improve the lives of this highly vulnerable group, for example in terms of alleviating the mental and physical health implications of disempowerment, alienation, and low self-esteem. At the very least, procedural justice might mean police can avoid contributing to and exacerbating these problems.

The police and local authorities have at their disposal a range of powers to tackle nuisance activities (House of Commons, 2019). Clearly, police and local authorities should strike a balance between the needs of rough sleepers and the concerns of local residents when deciding to use these powers. And as for any other group of people, enforcement measures against the street population should be used as a last resort, and only when they are used in combination with tailored support strategies. But our findings above suggest that police should adopt procedurally just policing approaches when dealing with the homeless to avoid stigmatization and perhaps even promote inclusion. Without this, police risk further marginalizing the street population and making it even more difficult for them to rebuild a life off the streets. Voluntary sector organisations have voiced concerns that existing policies to tackle rough sleeping in the UK criminalize homelessness rather than address the root cause of the problem, leaving vulnerable people in an even more marginalized position (House of Commons, 2019); procedural injustice in the policing of this group will only exacerbate such concerns, and indeed the underlying problems involved.

The current paper highlights that the four components of procedural justice (i.e., dignity and respect, trustworthiness, neutrality and voice) should still be important constituent parts of police training programs, since this is an approach that can foster bonds of solidarity and cooperation among diverse populations. Given the insights gathered here, it is important to also explore and test how the police can deliver the four principles 'on the ground' in the dynamic and complex situations in which they encounter members of the public. This creates a challenge because interventions are often based on creating procedurally just 'scripts' or crib sheets for officers in an effort to promote fair police treatment (MacQueen \& Bradford, 2015). Instead, a useful approach to training would revolve around the production of a series of 'real-life' scenarios that could be used to provoke discussion and reflection amongst officers on the kinds of issues and judgments that they may need to make in order to achieve procedural fairness in different situations with different groups and communities (c.f., Radburn \& Stott, 2018). The development of training scenarios or vignettes would usefully draw on examples from ethnographic research focused on interactions between marginalized communities and the police ([authors anonymised], XXXXa).

Positive steps forward in law enforcement and community relations, however, can only be achieved when the effort is collective. Policy implications of our work therefore extend beyond police training to the responsibility of the government and indeed other actors to take action as well. While many communities enjoy a strong and productive relationship with the police, in others profound fractures exist - and this is especially in the case of minority or economically disadvantaged communities. Existing research, including that reported in this paper, has helped us to understand a great deal about what is needed to build and maintain police-community trust: the elements of what is required to do so have been brought together in the concept of procedural justice. Fully implementing the principles or components of procedural justice is not easy, as they have implications not just for communication with the public but for policing tactics, strategies, accountability, discipline, and other internal processes. But they provide a roadmap for building trust between law enforcement and the community, and they are also integral in agency-level approaches, such as community policing, where building relationships with the public help both to educate citizens about the police and to educate the police about what the community needs them to do. The findings presented here adds to this research by demonstrating that even among a group as marginalized as people experiencing homelessness - who are also frequent 
'customers' of police - procedural justice may still be an important way to generate positive policepublic relationships.

Yet, although trust building at the local level is important, concentrating on a particularly marginalized group as we have here underlines that government and other authorities also have an important role to play. In particular, government needs to provide a policy environment which retains and supports the idea of positive police-community relations even - and perhaps especially - among marginalized communities. As noted above, procedurally just policing will only produce positive benefits for police and policed if the material reality of the latter is such that it enables, or at least does not fundamentally inhibit, the interactional processes envisaged by the theory. If policing the street population was by law and design all about enforcement, there would be a danger that more consent-based approaches would be crowded out. Contact with officers would almost inevitably exacerbate their marginalization, and there would be much greater potential for negative health and outcomes as a result of police contact (Geller et al. 2014). In short, it makes little sense of talk of police reform based on principles of procedural justice without also thinking of the tasks police are given, the laws they are asked to enact, and the wider policy environment within which they operate.

Finally, although our studies had several strengths, like all research it was also subject to several limitations. First, in Study 1 we could not uncover which social categories underpin relational identification with the police. It is for future work to explore this important issue. Second, we provided cross-sectional data and therefore we cannot claim causality. Third, we measured only intentions to cooperate, rather than acts. Fourth, we relied on non-probability samples. Further investigation is required to substantiate our findings - in the form of experimental research that goes beyond the correlational design of the present study and/or in the form of qualitative research. Regarding the latter, ethnographic work ([authors anonymised], XXXXa) has demonstrated that policing the street population is unsurprisingly complex. That is, interactions between police and homeless people are characterised by a structural context of disempowerment and therefore to understand how police encounters are framed in terms of fairness and legitimacy that might promote cooperation behavior, encounters should be studied as a subjective and dynamic process that surveys are ill-suited to capture.

\section{Conclusion}

We used a general population sample to show that the pathway between procedural justice and cooperation may be more complicated than is often proposed in the literature. There are multiple ways in which procedural justices promotes cooperation: through identification with the police, with an identity they represent ('the law-abiding'), and legitimacy. For members of the street population in London, however, perceptions of police legitimacy were not drivers of cooperation: police procedural justice was associated with cooperation behavior among members of the street population but only to the extent that they identified with the groups police represent. It therefore appears that among this highly marginalized group the social psychology of procedural justice, identity and cooperation is more similar to the general population's than might otherwise be assumed. Police activity seems to be identity-relevant even for people living at the extremes of society. Moreover, the 'power' of procedural justice seems to extend beyond people's judgements about the police to their judgements about themselves. Judgements of police procedural justice were associated with all three identity measures included in Study 2. This has important practical implications about the extent to which police activity can serve to include - or exclude - members of the public; and, in turn, how group internalization affects cooperation for this marginalized group.

This work was supported by the Economic and Social Research Council [grant number anonymised]. 
Tables

Table 1. Study 1: Demographic characteristics of sample

\begin{tabular}{llll}
\hline Sample characteristic & & Percentage of sample $^{1}$ & $\mathrm{~N}$ \\
\hline Gender & Male & $49.8 \%$ & 253 \\
& Female & $50.2 \%$ & 255 \\
Age range & $18-24$ & $10.8 \%$ & 55 \\
& $25-44$ & $39.5 \%$ & 201 \\
& $45-64$ & $39.3 \%$ & 200 \\
Ethnicity & $65+$ & $10.4 \%$ & 53 \\
& White British & $86.6 \%$ & 439 \\
& Asian & $6.3 \%$ & 32 \\
& Black & $2.8 \%$ & 14 \\
Country of birth & Mixed & $3.7 \%$ & 19 \\
& Other & $0.6 \%$ & 3 \\
& UK & $88.2 \%$ & 447 \\
\hline
\end{tabular}

${ }^{1}$ Percentages calculated with missing values excluded 
Table 2. Study 1: Descriptive statistics and covariances between latent constructs

\begin{tabular}{lcllll}
\hline & Variance & 1 & 2 & 3 & 4 \\
\hline 1. Police PJ & .50 & & & & \\
2. Relational ID & .85 & $\mathbf{. 4 2} * * *$ & & & \\
3. Superordinate ID & .73 & $\mathbf{. 2 1} * * *$ & $\mathbf{. 3 9} * * *$ & & \\
4. Legitimacy & .64 & $\mathbf{. 3 6} * * *$ & $\mathbf{. 5 4} * * *$ & $\mathbf{. 3 8 * * *}$ & \\
5. Cooperation & .79 & $\mathbf{. 2 6} * * *$ & $\mathbf{. 4 7} * * *$ & $\mathbf{. 3 9} * * *$ & $\mathbf{3 8 * * *}$ \\
\hline
\end{tabular}

$* * * p<.001$

Note: all indicators set as ordinal categorical variables 
Table 3. Standardized regression coefficients for direct and indirect paths in the study 1 SEM model

\begin{tabular}{|c|c|c|}
\hline Direct paths & & $B$ \\
\hline \multirow[t]{3}{*}{ Police PJ to } & Police ID & $.64 * * *$ \\
\hline & Superordinate ID & $.31 * * *$ \\
\hline & Legitimacy & $.26 * * *$ \\
\hline \multirow[t]{2}{*}{ Police ID to } & Legitimacy & $.44 * * *$ \\
\hline & Cooperation & $.32 * * *$ \\
\hline \multirow[t]{2}{*}{ Superordinate ID to } & Legitimacy & $.26 * * *$ \\
\hline & Cooperation & $.27 * * *$ \\
\hline Legitimacy to & Cooperation & $.16 *$ \\
\hline Indirect paths & & $B$ \\
\hline \multirow[t]{5}{*}{ Police PJ to cooperation via } & Police ID & $.21 * * *$ \\
\hline & Superordinate ID & $.08 * *$ \\
\hline & Legitimacy & .04 \\
\hline & Police ID $\rightarrow$ Legitimacy & $.04 *$ \\
\hline & Superordinate ID $\rightarrow$ Legitimacy & .01 \\
\hline
\end{tabular}

$* \mathrm{p}<.05, * * \mathrm{p}<.01, * * * \mathrm{p}<.001$

Note: all indicators set as ordinal categorical variables. Controls: age, gender, ethnicity and born in the UK 
Table 4. Study 2: Descriptive statistics and covariances between latent constructs

\begin{tabular}{lllllll}
\hline & Variance & 1 & 2 & 3 & 4 & 5 \\
\hline 1. Police PJ & .77 & & & & & \\
2. Police legitimacy & .74 & $\mathbf{. 6 2} * * *$ & & & & \\
3. Homeless ID & .60 & .09 & .06 & & & \\
4. Police ID & .91 & $\mathbf{. 5 0} * * *$ & $\mathbf{. 5 5} * * *$ & $\mathbf{. 1 2} * *$ & & \\
5. Superordinate ID & .86 & $\mathbf{. 3 6} * * *$ & $\mathbf{. 3 9} * * *$ & .07 & $\mathbf{. 4 3} * * *$ & \\
6. Cooperation & .97 & $\mathbf{. 4 6} * * *$ & $\mathbf{. 4 7} * * *$ & .07 & $\mathbf{. 5 4} * * *$ & $\mathbf{. 5 1 * * *}$ \\
\hline
\end{tabular}

$* * * p<.001, * * p<.05$

Note: all indicators set as ordinal categorical variables 
Table 5. Standardized regression coefficients for direct and indirect paths in the study 2 SEM model

\begin{tabular}{|c|c|c|c|}
\hline Direct paths & & $\mathrm{b}$ & $\mathrm{SE}$ \\
\hline \multirow[t]{5}{*}{ Police PJ to } & Homeless ID & $.18 *$ & .07 \\
\hline & Police ID & $.54 * *$ & .05 \\
\hline & Superordinate ID & $.46^{* *}$ & .07 \\
\hline & Legitimacy & $.65^{* * *}$ & .04 \\
\hline & Cooperation & .18 & .11 \\
\hline \multirow[t]{2}{*}{ Homeless ID to } & Legitimacy & -.04 & .06 \\
\hline & Cooperation & .01 & .06 \\
\hline \multirow[t]{2}{*}{ Police ID to } & Legitimacy & $.26^{* *}$ & .05 \\
\hline & Cooperation & $.28 *$ & .08 \\
\hline \multirow[t]{2}{*}{ Superordinate ID to } & Legitimacy & .08 & .06 \\
\hline & Cooperation & $.32 * *$ & .06 \\
\hline Legitimacy to & Cooperation & .05 & .11 \\
\hline Indirect paths & & $\mathrm{b}$ & $\mathrm{SE}$ \\
\hline \multirow[t]{7}{*}{ Police PJ to cooperation via } & Homeless ID & .01 & .01 \\
\hline & Police ID & $.15^{*}$ & .05 \\
\hline & Superordinate ID & $.15^{* *}$ & .04 \\
\hline & Legitimacy & .03 & .07 \\
\hline & Homeless ID $\rightarrow$ Legitimacy & .01 & .01 \\
\hline & Police ID $\rightarrow$ Legitimacy & .01 & .02 \\
\hline & Superordinate ID $\rightarrow$ Legitimacy & .01 & .01 \\
\hline Homeless ID to cooperation via & Legitimacy & -.01 & .01 \\
\hline Police ID to cooperation via & Legitimacy & .01 & .03 \\
\hline Superordinate ID to cooperation via & Legitimacy & .01 & .01 \\
\hline \multirow[t]{3}{*}{ Police PJ to legitimacy via } & Homeless ID & -.01 & .01 \\
\hline & Police ID & $.14 * *$ & .03 \\
\hline & Superordinate ID & .04 & .02 \\
\hline
\end{tabular}

$* \mathrm{p}<.05$

$* * \mathrm{p}<.001$ 


\section{Figures}

Figure 1. Standardized regression coefficients for significant direct paths in the study 1 SEM model

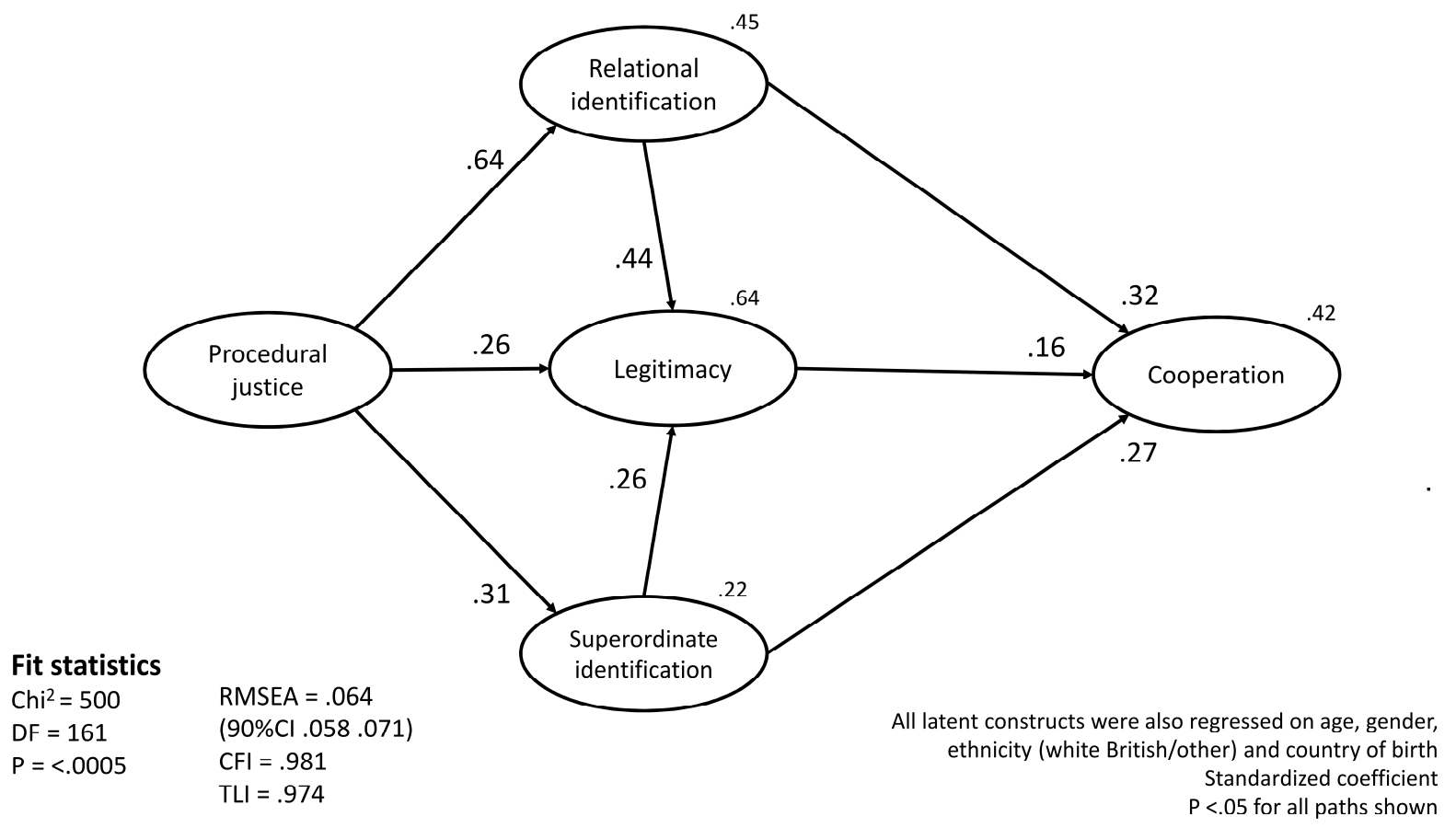


Figure 2. Standardized regression coefficients for significant direct paths in the Study 2 SEM model

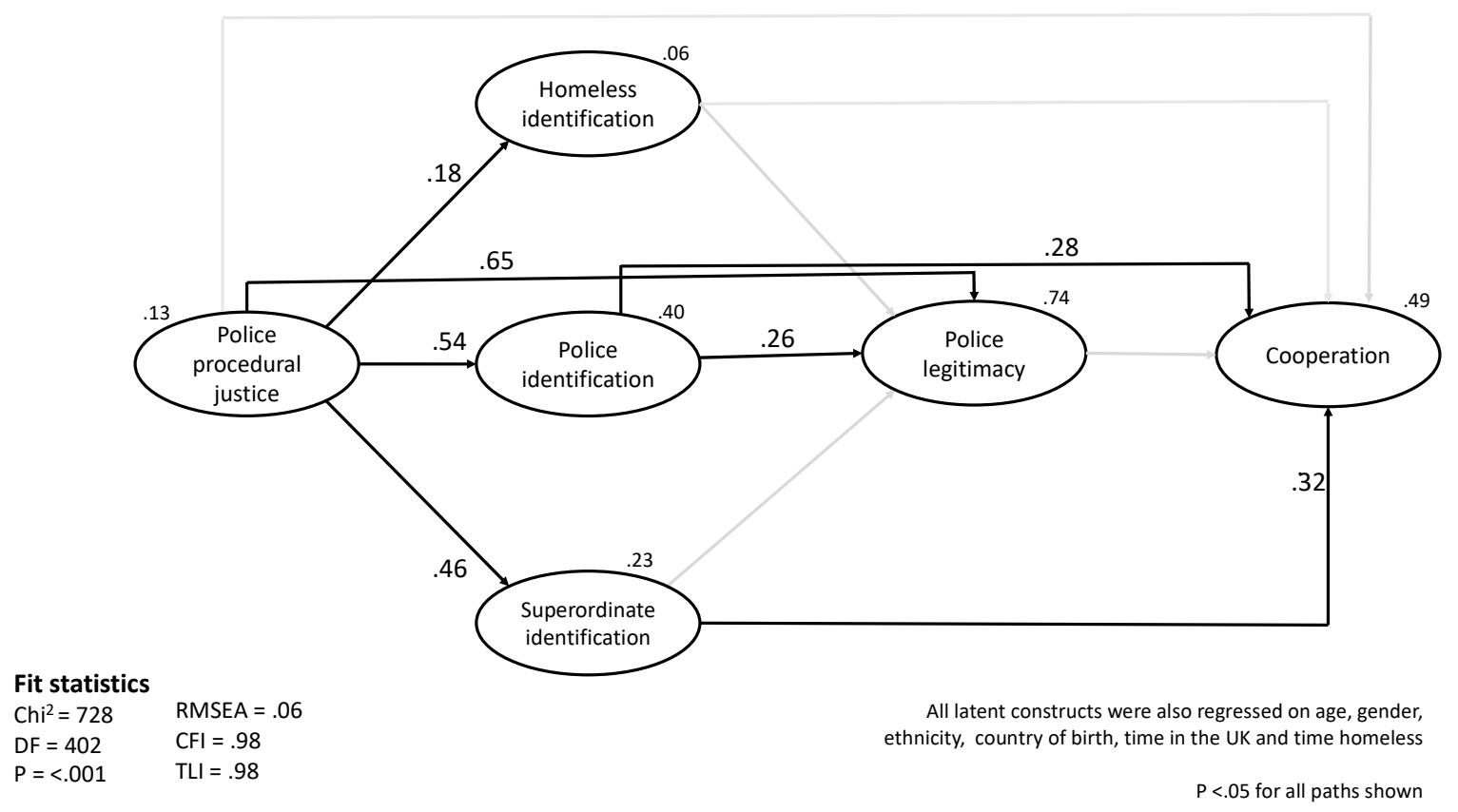


[authors anonymised] (XXXXa)

\section{References}

[authors anonymised] (XXXXb)

Bradford, B. (2014). Policing and social identity: Procedural justice, inclusion and cooperation between police and public. Policing and Society, 24, 22-43.

Bradford, B., Hohl, K., Jackson, J. \& MacQueen, S. (2015). Obeying the rules of the road: Procedural justice, social identity and normative compliance. Journal of Contemporary Criminal Justice, 31, 171-191.

Bradford, B., Murphy, K. \& Jackson, J. (2014). Officers as mirrors: Policing, procedural justice and the (re)production of social identity. British Journal of Criminology, 54, 527-550.

Belcher, J.R. \& DeForge, B.R. (2012). Social stigma and homelessness: The limits of social change. Journal of Human Behavior in the Social Environment, 22, 929-946.

Blader, S. L., \& Tyler, T. R. (2009). Testing and extending the group engagement model: Linkages between social identity, procedural justice, economic outcomes, and extrarole behavior. Journal of Applied Psychology, 94, 445-464.

Bottoms, A., \& Tankebe, J. (2012). Beyond procedural justice: A dialogic approach to legitimacy in criminal justice, Journal of Criminal Law and Criminology, 102/1, 119-170.

Geller, A., Fagan, J., Tyler, T.R. \& Link, B. (2014). Aggressive policing and mental health of young urban men. American Journal of Public Health, 104, 2321-2327.

Hamm, J. A., Trinkner, R., \& Carr, J. D. (2017). Fair process, trust, and cooperation: Moving toward an integrated framework of police legitimacy. Criminal Justice and Behavior, 44, 1183-1212.

Home Office (2012). Definition of policing by consent. FOI release: https://www.gov.uk/government/publications/policing-by-consent/definition-of-policing-byconsent

House of Commons (2019). Rough sleepers and anti-social behavior (England). House of Commons Library.

Huo, Y. (2003). Procedural justice and social regulation across group boundaries: Does subgroup identity undermine relationship-based governance? Personality and Social Psychology Bulletin, 29, 336-348.

Hu, L.-t., \& Bentler, P. M. (1999). Cutoff criteria for fit indexes in covariance structure analysis: Conventional criteria versus new alternatives. Structural Equation Modeling, 6, 1-55.

Huq, A.Z., Tyler, T.R., Schulhofer, S. (2011). Mechanisms for Eliciting Cooperation in Counterterrorism Policing: Evidence from the United Kingdom. Journal of Empirical Legal Studies, $8,728-761$.

Huq, A., Jackson, J. and Trinkner, R. (2017). Legitimating practices: Revisiting the predicates of police legitimacy. British Journal of Criminology, 57, 1101-1122.

Jackson, J. (2018). Norms, normativity and the legitimacy of legal authorities: International perspectives. Annual Review of Law and Social Science, 14, 145-165.

Jackson, J., Bradford, B., Hough, M., Myhill, A., Quinton, P., and Tyler, T. R. (2012). Why do people comply with the law? Legitimacy and the influence of legal institutions. British Journal of Criminology, 52, 1051-1071.

Jackson, J., Bradford, B., Stanko, E. A. and Hohl, K. (2013). Just Authority? Trust in the Police in England and Wales. Oxon: Routledge.

Jackson, J., \& Bradford, B. (2019). Blurring the distinction between empirical and normative legitimacy? A methodological commentary on "police legitimacy and citizen cooperation in China". Asian Journal of Criminology, 14, 265-289.

Jackson, J., Brunton-Smith, I., Bradford, B., Rodriguez-Oliveira, T., Posch, K. and Sturgis, P. (2020). Police legitimacy and the norm to cooperate: Using a mixed effects location-scale model to estimate social norms at a small spatial scale. Journal of Quantitative Criminology, https://doi.org/10.1007/s10940-020-09467-5

Jackson, J. and Gau, J. (2016). Carving up concepts? Differentiating between trust and legitimacy in public attitudes towards legal authority. In Shockley, E., Neal, T. M. S., PytlikZillig, L. and Bornstein, B. (eds.) Interdisciplinary Perspectives on Trust: Towards Theoretical and Methodological Integration. New York: Springer, pp. 49-69.

Jackson, J., Pósch, K., Oliveira, T. R., Bradford, B., Mendes, S. M., Natal, A. L., \& Zanetic, A. (2021, 
January 28). Fear and legitimacy in São Paulo, Brazil: Police-citizen relations in a high violence, high fear city. Available at PsyArXiv: https://doi.org/10.31235/osf.io/3awrz.

Jackson, J., Bradford, B., Giacomantonio, C., \& Mugford, R. (2020). Developing core national indicators of public attitudes towards the police in Canada. Available at SocArXiv: https://doi.org/10.31235/osf.io/fea62

Jonathan-Zamir, T. Mastrofski, S.D. \& Moyal, S. (2015). Measuring procedural justice in police-citizen encounters, Justice Quarterly, 32:5, 845-871

Kline, R. B. (2011). Methodology in the Social Sciences: Principles and practice of structural equation modeling (3rd ed.). Guilford Press.

Kochel, T., Parks, R. and Mastrofski, S. (2013). Examining police effectiveness as a precursor to legitimacy and cooperation with police. Justice Quarterly, 30, 895- 925.

Leach, C. W., van Zomeren, M., Zebel, S., Vliek, M. L. W., Pennekamp, S. F., Doosje, B., \& Ouwerkerk, J. W. (2008). Group-level self-definition and self-investment: A hierarchical (multicomponent) model of in-group identification. Journal of Personality and Social Psychology, 95, 144-165.

Lind, E. A., \& Tyler, T. R. (1988). The social psychology of procedural justice. Plenum Press.

MacQueen, S., \& Bradford, B. (2015). Enhancing public trust and police legitimacy during road traffic encounters: Results from a randomised controlled trial in Scotland. Journal of Experimental Criminology, 11, 419-443.

Madon, N., Murphy, K., \& Cherney, A. (2016). Promoting community collaboration in counterterrorism: Do social identities and perceptions of legitimacy mediate reactions to procedural justice policing? British Journal of Criminology, 57, 1144-1164.

Maruna, S., Lebel, T. P., Mitchell, N., \& Naples, M. (2004). Pygmalion in the reintegration process: Desistance from crime through the looking glass. Psychology, Crime \& Law, 10, 271-281.

Mazerolle, L., Antrobus, E., Bennett, S., Tyler, T. (2013). Shaping citizen perceptions of police legitimacy: A randomized field trial of procedural justice. Criminology, 51, 33-64.

Mentovich, A. (2012). The Power of Fair Procedures - The Effect of Procedural Justice on Perceptions of Power and Hierarchy. New York University.

Murphy, K. \& Barkworth, J. (2014). Victim willingness to report crime to police: Does procedural justice or outcome matter most? Victims and Offenders, 9, 178-204.

Murphy, K., Hinds, L., \& Fleming, J. (2008). Encouraging cooperation and public support for police. Policing and Society, 18, 138-157.

Murphy, K., Cherney, A. (2011). Fostering cooperation with the police: How do ethnic minorities in Australia respond to procedural justice-based policing? Australian \& New Zealand Journal of Criminology, 44, 235-57.

Murphy, K., Cherney, A. (2012). Understanding cooperation with police in a diverse society. British Journal of Criminology, 52, 181-201.

Murphy, K (2013) Policing at the margins: Fostering trust and cooperation among ethnic minority groups. Journal of Policing, Intelligence and Counter Terrorism, 8, 184-199.

Murphy, K., Bradford, B., Sargeant, E., \& Cherney, A. (2020). Enhancing immigrants' willingness to cooperate with police: The importance of procedural justice and identifying with police. Manuscript submitted for publication.

Murphy, K., Sargeant, E., \& Cherney, A. (2015). 'The importance of procedural justice and police performance in shaping intentions to cooperate with the police: Does social identity matter?', European Journal of Criminology, 12, 719-738.

Nagin, D.S. \& Telep, C.W. (2020). Procedural justice and legal compliance: a revisionist perspective. Criminology \& Public Policy. DOI: 10.1111/1745-9133.12499.

Oliveira, T. R., Jackson, J., Murphy, K. and Bradford, B.. (2020). Are trustworthiness and legitimacy "hard to win, easy to lose"? A longitudinal test of the asymmetry thesis of police-citizen contact. Journal of Quantitative Criminology, https://doi.org/10.1007/s10940-020-09478-2.

ONS (2017). Population estimates for the UK, England and Wales, Scotland and Northern Ireland: mid2017.

Posch, K., Jackson, J., Bradford, B. and MacQueen, S. (2020). "Truly free consent”? Clarifying the nature of police legitimacy using causal mediation analysis. Journal of Experimental Criminology, https://doi.org/10.1007/s11292-020-09426-x. 
Radburn, M., Stott, C., Robinson, M., \& Bradford, B. (2016) When is policing fair? Groups, identity and judgements of the procedural justice of coercive crowd policing. Policing and Society, 28, 647664.

Radburn, M., \& Stott, C. (2018) The social psychological processes of 'procedural justice': Concepts, critiques and opportunities. Criminology \& Criminal Justice, 19, 421-438.

Reisig, M. D., Bratton, J., \& Gertz, M. G. (2007). The construct validity and refinement of processbased policing measures. Criminal Justice and Behavior, 34, 1005-1028.

Sargeant, E. Antrobus, E., Murphy, K., Bennett, S. \& Mazerolle, L. (2016). Social identity and procedural justice in police encounters with the public: Results from a randomized controlled trial. Policing and Society, 26, 789-803.

Sideridis G, Simos P, Papanicolaou A, Fletcher J (2014). Using structural equation modeling to assess functional connectivity in the brain: Power and sample size considerations. Educational and Psychological Measurement, 74, 733-758.

Stott, C., Hoggett, J. and Pearson, G. (2012) 'Keeping the Peace': Social Identity, Procedural Justice and the Policing of Football Crowds. British Journal of Criminology, 52, 381-399.

Sunshine, J., Tyler, T. (2003). The role of procedural justice and legitimacy in shaping public support for policing. Law and Society Review, 37, 513-47.

Tajfel, H., \& Turner, J. C. (1979). An integrative theory of intergroup conflict. In W. G. Austin, \& S. Worchel (Eds.), The Social Psychology of Intergroup Relations (pp. 33-47). Monterey, CA: Brooks/Cole.

Tankebe, J. (2009). Public Cooperation with the Police in Ghana: Does Procedural Fairness Matter? Criminology: An International Journal 47(4): 1265-1293.

Tankebe, J. (2013). Viewing things differently: The dimensions of public perceptions of police legitimacy. Criminology: An Interdisciplinary Journal, 51(1), 103-135.

Trinkner, R. (2019). Clarifying the Contours of the Police Legitimacy Measurement Debate: A Response to Cao and Graham. Asian Journal of Criminology, 14(4), 309-335.

Trinkner, R., Jackson, J., \& Tyler, T. R. (2018). Bounded authority: Expanding "appropriate" police behavior beyond procedural justice. Law and Human Behavior, 42, 280-293.

Turner, J. C., Oakes, P. J., Haslam, S. A., \& McGarty, C. (1994). Self and collective: Cognition and social context. Personality and Social Psychology Bulletin, 20, 454-463.

Turner, J. C., Hogg, M. A., Oakes, P. J., Reicher, S., \& Wetherell, M. (1987). Rediscovering the social group: A self-categorisation theory. Oxford, UK: Blackwell.

Tyler, T. \& Blader, S. (2000). Cooperation in Groups. New York: Routledge.

Tyler, T. R., \& Blader, S. L. (2003). The Group Engagement Model: Procedural justice, social identity, and cooperative behavior. Personality and Social Psychology Review, 7, 349-361.

Tyler, T. R., \& J. Fagan (2008), Legitimacy and cooperation: Why do people help the police fight crime in their communities?, Ohio State Journal of Criminal Law, 6, 231-275.

Tyler, T. R., \& Jackson, J. (2013). Popular legitimacy and the exercise of legal authority: Motivating compliance, cooperation, and engagement. Psychology, Public Policy, and Law, 20(1), 78-95.

Tyler, T. R., Jackson, J. \& Mentovich, A. (2015). On the consequences of being a target of suspicion: Potential pitfalls of proactive police contact. Journal of Empirical Legal Studies, 12, 4, 602-636.

Tyler, T. (2006). Psychological perspectives on legitimacy and legitimation. Annual Review of Psychology, 57, 375-400.

Tyler, T. (1990). Why people obey the law. New Haven, CT: Yale University Press.

Tyler, T. R. (1997). The psychology of legitimacy: A relational perspective on voluntary deference to authorities. Personality and Social Psychology Review, 1(4), 323-345.

Tyler, T. \& Huo, Y. (2002). Trust in the Law. New York: Russell Sage.

Tyler, T. R. (2011). Why people cooperate: The role of social motivation. Princeton University Press.

Walters, G.D., \& Bolger, P.C. (2019). Procedural justice perceptions, legitimacy beliefs, and compliance with the law: a meta-analysis. Journal of Experimental Criminology, 15, 341-372.

White, M. D., Mulvey, P., \& Dario, L. M. (2016). Arrestees' perceptions of the police: exploring procedural justice, legitimacy, and willingness to cooperate with police across offender types. Criminal Justice and Behavior, 43, 343-364. 
Wolf, E. J., Harrington, K. M., Clark, S. L., \& Miller, M. W. (2013). Sample Size Requirements for Structural Equation Models: An Evaluation of Power, Bias, and Solution Propriety. Educational and Psychological Measurement, 76, 913-934.

Wright, K.B. (2005). Researching Internet-Based Populations: Advantages and Disadvantages of Online Survey Research, Online Questionnaire Authoring Software Packages, and Web Survey Services, Journal of Computer-Mediated Communication, 10(3).

Yesberg, J.A., Bradford, B. \& Dawson, P. (2020). An experimental study of responses to armed police in Great Britain. Journal of Experimental Criminology. https://doi.org/10.1007/s11292-019-094088. 


\section{Appendix}

Item wordings and factor loadings for latent variables used in analysis

\begin{tabular}{cc}
\multicolumn{2}{c}{ Factor } \\
loadings \\
\hline Study & Study \\
1 & 2 \\
\hline
\end{tabular}

\section{Procedural justice}

Study 1 Procedural justice (Jackson et al., 2020)

The police explain their decisions to the people they deal with

.698

The police would treat you with respect if you had contact with them for any reason

.916

Study 2 Procedural justice (Jackson \& Bradford, 2019)

The police make decisions based on facts

The police explain their decisions to the people they deal with 910

The police treat people with respect

\section{Police legitimacy}

Study 1 Duty to obey (Trinkner et al., 2018)

It is my moral duty to back the decisions made by the police because the police are legitimate authorities

It is my moral duty to support the decisions of police officers, even if I disagree with them

It is my moral duty to do what the police tell me even if I don't understand or agree with the reasons

Study 2 Duty to obey (Trinkner et al., 2018)

I feel a moral obligation to obey the police

I feel a moral duty to support the decisions of police officers, even if I disagree with them

I feel a moral duty to obey the instructions of police officers, even when I don't understand the

reasons behind them

Study 1 Normative alignment (Posch et al., 2020)

The police can be trusted to make the right decisions

The police stand up for moral values that are important for people like me

The police usually act in ways that are consistent with my own ideas about what is right and wrong

Study 2 Normative alignment (Trinkner et al., 2018)

I support the way the police usually act

The police usually act in ways that are consistent with my own ideas about what is right and wrong

The police stand up for values that are important for people like me

\section{Relational identification with the police (Radburn et al. 2016)}

I identify with the police

I feel a sense of solidarity with the police

I feel similar to the police

Superordinate identification (Bradford et al., 2015)

I see myself as an honest, law-abiding citizen

It is important to me to be seen by others as an honest, law-abiding citizen

\section{Homeless identification (study 2 only; Leach et al., 2008)}

I feel a bond with other homeless people

I feel solidarity with other homeless people

Being homeless gives me a good feeling

I think that homeless people have a lot to be proud of

I often think about the fact that I am homeless 
Being homeless is an important part of how I see myself $\quad .888$

$\begin{array}{ll}\text { I have a lot in common with the average homeless person } & .961\end{array}$

I am similar to the average homeless person $\quad .992$

Homeless people have a lot in common with each other $\quad .860$

Homeless people are very similar to each other $\quad .806$

\section{Cooperation with the police}

Study 1 Cooperation with the police (Jackson et al., 2013)

If the situation arose I would call the police to report a crime I witnessed $\quad .889$

If the situation arose I would report suspicious activity near my house to the police $\quad .890$

If the situation arose I would provide information to the police to help find a suspected criminal $\quad .918$

Study 2 Cooperation with the police (Jackson et al., 2020)

I would help the police if asked, e.g. identify someone wanted of a crime if I could help $\quad .983$

I would go to the police for assistance (e.g. if I was a victim of crime)

Fit indices Study $1: \chi^{2}(94)=450, \mathrm{p}<.001 ;$ RMSEA $=.086[.078, .094] ; \mathrm{CFI}=.980 ; \mathrm{TLI}=.974$

Fit indices Study 2: $\chi^{2}(282)=617, \mathrm{p}<.001 ; \mathrm{RMSEA}=.078[.069, .086] ; \mathrm{CFI}=.981 ; \mathrm{TLI}=.978$ 